CLINICAL STUDY

\title{
Endocrine dysfunction in patients operated on for non-pituitary intracranial tumors
}

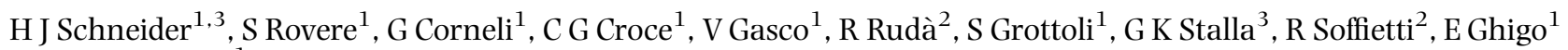 \\ and $\mathrm{G}$ Aimaretti ${ }^{1}$ \\ ${ }^{1}$ Division of Endocrinology and Metabolism, Department of Internal Medicine, and ${ }^{2}$ Division of Neurology, University of Turin, C.so Dogliotti, 14,10126 \\ Turin, Italy and ${ }^{3}$ Internal Medicine/Endocrinology and Clinical Chemistry, Max Planck Institute of Psychiatry, Munich, Germany \\ (Correspondence should be addressed to G Aimaretti; Email: gianluca.aimaretti@unito.it)
}

\begin{abstract}
Objective: Hypopituitarism frequently follows pituitary neurosurgery (NS) and/or irradiation. However, the frequency of hypothalamic-pituitary dysfunction after NS of non-pituitary intracranial tumors is unclear. The aim of this study was to assess the presence of endocrine alterations in patients operated on for intracranial tumors.

Design: This is a retrospective study.

Methods: We studied 68 consecutive adult patients ( 28 female, 40 male, age $45.0 \pm 1.8$ years; body mass index (BMI): $26.5 \pm 0.6)$ with intracranial tumors who underwent NS only $(n=17)$ or in combination with radiotherapy (RT) and/or chemotherapy (CT) $(n=51)$. In all subjects, basal endocrine parameters and the GH response to GHRH+ arginine test (using BMI-dependent cut offs) were evaluated.

Results: In $20.6 \%$ of the patients, peripheral endocrinopathy related to CT and/or RT was present. Hypopituitarism was found in $38.2 \%$ of the patients. Total pituitary hormone, multiple pituitary hormone, and isolated pituitary hormone deficits were present in 16.2, 5.8, and 16.2\% respectively. The most common pituitary deficits were, in decreasing order: LH/FSH 29.4\%, GH 27.9\%, ACTH $19.1 \%$, TSH $17.7 \%$, and diabetes insipidus 4.4\%. Hyperprolactinemia was present in $13.2 \%$. The prevalence of hypopituitarism was higher in patients who underwent NS only and with tumors located closely to the sella turcica, but a substantial proportion of patients with tumors not directly neighboring the sella also showed hypopituitarism.

Conclusions: Hypopituitarism frequently occurs after NS for intracranial tumors. Also, exposure of these patients to CT and/or RT is frequently associated with peripheral endocrinopathies. Thus, endocrine evaluation and follow-up of patients treated for intracranial tumors should be performed on a regular basis.
\end{abstract}

European Journal of Endocrinology 155 559-566

\section{Introduction}

Pituitary dysfunction as a consequence of intrasellar tumor masses originating from the pituitary or Rathke's pouch is a well-known problem. Here, pituitary dysfunction can be caused by the tumor itself or by further damage due to surgery, radiotherapy, or medical therapies (1). Analyses of large series in experienced neurosurgical centers suggest impairment of pituitary function in $80-100 \%$ of patients operated on for nonfunctioning pituitary adenomas $(1,2)$, and total hypopituitarism in more than $40 \%$ of patients treated for craniopharyngeomas (3). Moreover, patients who have received radiotherapy (RT) for tumors of the pituitary (4), nasopharyngeal cancers (5), tumors of the skull base, and childhood cancers have been found to be at high risk of pituitary dysfunction (reviewed in (6)). In a more recent study, a substantial degree of pituitary impairment was also found in adult patients irradiated for non-pituitary tumors (7).

Recent evidence shows that pituitary dysfunction is also a common problem in patients with brain damage not directly related to the pituitary, such as traumatic brain injury (8-10) and subarachnoid hemorrhage $(9,11)$. The mechanisms involved herein are still poorly understood. Necrosis, infarction, and hemorrhage into the pituitary and hypothalamus were found in a large proportion of subjects, who did not survive traumatic brain injury and subarachnoid hemorrhage (reviewed in (12)). These factors could also play a potential role in survivors.

Taking this into account, we assumed that pituitary dysfunction can also be present in brain damage due to tumors (and their surgical treatment) that do not originate from the pituitary. Moreover, accompanying treatment such as chemotherapy (CT) or irradiation might cause additional hormonal insufficiencies of both central and 
peripheral glands. Therefore, we examined pituitary function in a population of patients with non-pituitary brain tumors that were treated with neurosurgery (NS). Additionally, we also wanted to assess the presence of peripheral hormone alterations in this population.

\section{Subjects and methods}

\section{Subjects}

We studied 68 consecutive adult patients (40 male, 28 female, age range: $20-79$ years, mean \pm s.E.M.: $45.0 \pm$ 1.8 years; body mass index (BMI) range: 16.0-43.0, mean \pm s.e.M.: $26.5 \pm 0.6)$ treated neurosurgically for glioma $(n=40)$, meningioma $(n=18)$, schwannoma $(n=5)$, dysgerminoma $(n=2)$, neuroblastoma $(n=1)$, chondrosarcoma $(n=1)$, hemangiopericytoma $(n=1)$, and osteosarcoma $(n=1)$. Of these, 17 underwent NS only, 24 NS and RT, seven NS and CT, and 20 patients had NS, RT, and CT. The endocrine assessments were carried out consecutively due to clinical suspicion of hormone deficiencies to exclude endocrine dysfunction. We used the standardized protocol routinely used for detection of hypopituitarism in the Endocrine Outpatient Clinic of the University of Turin as described later and analyzed the data retrospectively. We included all patients aged 18 years or older with hormonal evaluations, who were operated on for the analysis of brain tumors. We did not analyze patients without neurosurgical treatments. All patients gave informed consent. No patient had known neuroendocrine disease before the tumor was diagnosed. Five patients were under glucocorticoid treatment during the study. We excluded these patients from the analysis of corticotropic function.

\section{Localization of tumors}

We divided the localization sites of the tumors into four regional subgroups with regard to proximity of the hypothalamic-pituitary region that included the following areas; group 1 (central region): sphenoid, clinoid, tuberculum sellae, sella, supra-, infra- and parasellar, and third ventricle; group 2 (frontal region): frontal, fronto-temporal, fronto-parietal, fronto-basal, and ethmoid; group 3 (temporal/parietal region): parietal, temporal, parieto-occipital, temporo-parietal, lateral ventricles, and acoustic nerve; and group 4 (occipital region): occipital, cerebellum, pineal gland, and fourth ventricle.

\section{Endocrine evaluation}

Endocrine function was tested as follows: (a) $0900 \mathrm{~h}$ serum cortisol and 24-h urinary free cortisol (UFC) levels; (b) free triiodothyronine (fT3), free thyroxine (fT4), and thyroid-stimulating hormone (TSH) levels; (c) prolactin (PRL), follicle-stimulating hormone (FSH), luteinizing hormone (LH), and testosterone (men) or
$17 \beta$-estradiol (E2) (women) levels; and (d) diuresis, urine density, $\mathrm{Na}++$, and plasma osmolality.

The function of the growth hormone $(\mathrm{GH}) /$ insulin-like growth factor-I (IGF-I) axis was evaluated by GH-releasing hormone $(\mathrm{GHRH})(1 \mu \mathrm{g} / \mathrm{kg}$ i.v. at $0 \mathrm{~min})$ plus arginine (arginine hydrochloride, vials of $30 \mathrm{~g}$ in $100 \mathrm{ml}$, to be administered as i.v. infusion over $30 \mathrm{~min}$ from 0 to $+30 \mathrm{~min}$ at dose of $0.5 \mathrm{~g} / \mathrm{kg}$ up to a maximum of $30 \mathrm{~g}$ ) test $(13,14)$; $\mathrm{GH}$ assays were performed at $+30,+45,+60$, and +90 min. Total IGF-I levels were additionally analyzed.

\section{Definitions of hormonal impairment}

Diabetes insipidus was defined as the presence of massive dilute urine volume $(>2.5-3 \mathrm{l} / 24 \mathrm{~h})$ with low urine osmolality $(<300 \mathrm{mmol} / \mathrm{kg})$. Secondary adrenal insufficiency was defined as early morning (0900 h) cortisol concentrations $<80 \mu \mathrm{g} / \mathrm{l}$ in association with low 24-h urinary free cortisol levels $(<30 \mu \mathrm{g} / 24 \mathrm{~h})$. Secondary hypothyroidism was defined as low fT4 $(<8 \mathrm{ng} / \mathrm{l})$ concentrations with normal or low normal TSH levels. Secondary hypogonadism was defined as; (i) in premenopausal women, menstrual disturbances, low estradiol levels $(<20 \mathrm{pg} / \mathrm{ml})$ with normal or low FSH and LH levels; (ii) in postmenopausal women, inappropriately low FSH and LH levels; (iii) in men, low testosterone levels $(<3 \mu \mathrm{g} / \mathrm{l})$ with low or normal FSH and LH levels.

GH deficiency (GHD) was demonstrated by peak GH response to GHRH + arginine test according to BMIdependent cut offs as described by Corneli et al. (15). Thus, severe GHD was defined as peak GH $<11.5$, 8.0, and $4.2 \mathrm{ng} / \mathrm{ml}$ in subjects with a BMI $\leq 25,25-30$, and $>30$ respectively. IGF-I levels were considered with respect to the 25 th centile and -2 SDS age-related normal limits. Peripheral impairment of the gonadal axis was assumed, if gonadotropins were elevated and testosterone levels were low in men and there was amenorrhea in premenopausal women.

Postmenopausal women could not be evaluated in this regard. Primary hypothyroidism was diagnosed if fT4 was decreased $(<8 \mathrm{ng} / \mathrm{l})$ and TSH increased. If thyroid peroxidase (TPO) antibodies were positive, we assumed autoimmune thyroiditis as the cause of hypothyroidism. Otherwise, we assumed it to be caused by radiation or chemotherapy, provided that there was no previous history of thyroid surgery.

\section{Assay methods}

Serum GH $(\mu \mathrm{g} / \mathrm{l})$ was measured in duplicate by IRMA (Dia Sorin, Saluggia, Italy). The sensitivity of the assay was $0.15 \mu \mathrm{g} / \mathrm{l}$ for $\mathrm{GH}$. The inter- and intra-assay coefficient of variation (CV) values were 3.5-4.4 and 5.1-7.5\% respectively at GH levels of 1.98-41.92 and 2.99$42.45 \mu \mathrm{g} / \mathrm{l}$ respectively. Serum IGF-I $(\mu \mathrm{g} / \mathrm{l})$ was measured by RIA (Nichols Institute Diagnostics, San Clemente, CA, 
USA) after acid-ethanol extraction to avoid interference by binding proteins. The sensitivity of the assay was $0.013 \mathrm{nmol} / \mathrm{l}$. The inter- and intra-assay CV values were 5.2-8.4 and 2.4-3.0\% respectively. Serum fT4 (ng/l) was measured by RIA (Techno Genetics, Cassina de' Pecchi, Milano, Italy). The sensitivity of the assay was $0.39 \mathrm{ng} / \mathrm{l}$. The inter- and intra-assay CV values were $6.6-8.7$ and $2.6-7.3 \%$ respectively.

Serum TSH (mU/l) was measured by IRMA (TSH Irma C.T., Biocode, Liege, Belgium). The sensitivity of the assay was $0.05 \mathrm{mU} / \mathrm{l}$. The inter- and intra-assay $\mathrm{CV}$ values were $4.2-7.1$ and $4.0-6.2 \%$ respectively.

Serum cortisol $(\mu \mathrm{g} / \mathrm{l})$ was measured in duplicate by RIA (Dia Sorin). The sensitivity of the assay was $<0.5 \mu \mathrm{g} / \mathrm{l}$. The inter- and intra-assay $\mathrm{CV}$ values ranged from 6.6 to $7.5 \%$ and from 3.8 to $6.6 \%$ respectively.

UFC levels $(\mu \mathrm{g} / 24 \mathrm{~h})$ were evaluated by RIA kits (Biodata Diagnostics, SpA; Guidonia, Montecelio, Roma, Italy). The sensitivity of the assay was $7.36 \mu \mathrm{g} /$ day. The inter- and intra-assay $\mathrm{CV}$ values were $1.8-9.2$ and $3.2-4.6 \%$ respectively.

Serum PRL levels $(\mu \mathrm{g} / \mathrm{l})$ were measured in duplicate by IRMA (Dia Sorin). The sensitivity of the assay was $0.45 \mu \mathrm{g} / \mathrm{l}$. The inter- and intra-assay $\mathrm{CV}$ values ranged from 3.1 to 5.8 and 0.9 to $5.8 \%$ respectively.

Serum estradiol levels $(\mathrm{pg} / \mathrm{ml})$ were measured in duplicate by the RIA method (Diagnostic Products). The sensitivity of the assay was $1.4 \mathrm{pg} / \mathrm{ml}$. Inter- and intraassay CV values were 5.2-9.1 and 5.5-10.5\% respectively.

Serum testosterone levels $(\mathrm{ng} / \mathrm{ml})$ were measured in duplicate by the RIA method (Diasorin, Saluggia, Italy). The sensitivity of the assay was $0.05 \mathrm{ng} / \mathrm{ml}$. Inter- and intra-assay CV values were $11.3-13.7$ and $3.81-8.07 \%$ respectively.

Serum LH $(\mathrm{mIU} / \mathrm{ml})$ and $\mathrm{FSH}(\mathrm{mIU} / \mathrm{ml})$ levels were measured by IRMA kits. The sensitivities of the assay were 0.20 and $0.18 \mathrm{mIU} / \mathrm{ml}$. Inter- and intra-assays $\mathrm{CV}$ values were $5.8-13.8$ and $7.5-8.3 \%$ respectively.

\section{Statistical analysis}

The results are expressed as mean \pm s.E.m. and as percentage of abnormal response with respect to normative cut off levels. Correlations were calculated using the Pearson's correlation coefficient in case of normal distribution. Otherwise the Spearman's correlation coefficient was used. Differences between groups were tested with the Student's $t$-test or the Mann-Whitney's U-test in case of normal or uneven distribution respectively. A two-tailed $P$ value of $<0.05$ was regarded as significant.

\section{Results}

Tables 1 and 2 summarize the clinical characteristics of patients with central and peripheral hormone deficiencies respectively. The distribution of patients among regional subgroups was as follows: group 1 , $n=16$; group 2, $n=23$; group $3, n=18$; and group 4 , $n=10$. In one patient, information on localization was missing.

Figure 1 shows the distribution of hormonal deficiencies. A total of 30 patients $(44.1 \%)$ had no impairment of hormonal function. We found various degrees of hypopituitarism in 26 patients $(38.2 \%)$. Eleven patients (16.2\%) had total pituitary hormone deficits (TPHD), four patients $(5.8 \%)$ multiple pituitary hormone deficits (MPHD), and 11 patients (16.2\%) had isolated pituitary hormone deficits (IPHD). The percentages of pituitary deficits according to treatment were as follows: NS: 41.2\% (23.5\% TPHD; 0\% MPHD; $17.7 \%$ IPHD), NS and RT: 33.3\% (16.7\% TPHD; 8.3\% MPHD; 8.3\% IPHD), NS and CT: $28.6 \%$ (14.3\% TPHD; 0\% MPHD; 14.3\% IPHD), and NS, RT, and CT: 45\% (10\% TPHD; 10\% MPHD; 25\% IPHD). The percentage of deficits in all patients treated with RT and/or CT in addition to NS was $37.3 \%(13.7 \%$ TPHD; 7.8\% MPHD; 15.5\% IPHD; Fig. 2). Pituitary deficits according to regional subgroups of tumor localization were distributed as follows: group 1 (central): 68.8\% (62.5\% TPHD; 0\% MPHD; $6.3 \%$ IPHD), group 2 (frontal): $26 \%$ (0\% TPHD; 13\% MPHD; 13\% IPHD), group 3 (temporal/parietal): $22.2 \%(0 \%$ TPHD; $5.6 \%$ MPHD; $16.6 \%$ IPHD), and group 4 (occipital): $40 \%$ (only IPHD). Taken together, the percentage in the non-central groups $2-4$ was $27.4 \%$ (0\% TPHD; 7.8\% MPHD; 19.6\% IPHD; Fig. 2). Of those patients with tumors in the central and non-central region, 43.8 and $19.6 \%$ respectively were treated with NS only. The others were treated with NS and RT and/or CT. Among patients with tumors of the central region, the percentage of hypopituitarism in those treated with NS only and those treated with NS, RT, and/or CT were 57.1\% (57.1\% TPHD; 0\% MPHD; 0\% IPHD); $77.8 \%$ (66.7\% TPHD; 0\% MPHD; 11.1\% IPHD) respectively. Among those patients with tumors of the non-central region, the percentage of hypopituitarism in those treated with NS only and those treated with NS, RT, and/or CT were 33.3\% (0\% TPHD; 0\% MPHD; 33.3\% IPHD); $21.6 \%$ (0\% TPHD; $7.8 \%$ MPHD; $13.7 \%$ IPHD) respectively.

Impairment of LH/FSH secretion was the most common $(29.4 \%)$, followed by GH $(27.9 \%)$, adrenocorticotropic hormone (ACTH) (19.1\%), and TSH (17.7\%) deficiencies. Diabetes insipidus was present in three (4.4\%) patients, all of whom had TPHD. Hyperprolactinemia was present in nine patients $(13.2 \%)$, and two patients $(2.9 \%)$ had decreased prolactin levels. Two of these patients were on drugs known to elevate prolactin levels. Six of the nine patients with hyperprolactinemia had hypopituitarism. Therefore, $23.1 \%$ of the patients with hypopituitarism had hyperprolactinemia, whereas only $7.1 \%$ of those without hypopituitarism had hyperprolactinemia. 
Table 1 Clinical characteristics of patients with hypopituitarism.

\begin{tabular}{|c|c|c|c|c|c|c|c|c|c|c|c|}
\hline Patient & Sex & Age & $\begin{array}{c}\text { Body } \\
\text { mass } \\
\text { index } \\
(\mathrm{BMI})\end{array}$ & Tumor type & Localization & $\begin{array}{l}\text { Regional } \\
\text { group }\end{array}$ & Treatment & $\begin{array}{l}\text { Pituitary } \\
\text { deficits }\end{array}$ & $\begin{array}{l}\text { Peripheral } \\
\text { deficits }\end{array}$ & $\begin{array}{l}\text { Years } \\
\text { after } \\
\text { surgery }\end{array}$ & Remarks \\
\hline 1 & $M$ & 24 & 22.1 & Disgerminoma & Hypothalamus-pituitary & 1 & $\mathrm{NS}+\mathrm{CT}$ & $\mathrm{TPHD}+\mathrm{DI}$ & & 0.3 & Hyperpolactinemia \\
\hline 2 & $\mathrm{~F}$ & 58 & 27.9 & Transitional meningioma & Tuberculum sellae & 1 & $\mathrm{NS}+\mathrm{RT}$ & TPHD+DI & & 1 & Hyperpolactinemia \\
\hline 3 & $\mathrm{~F}$ & 28 & 20.8 & $\begin{array}{l}\text { Pilocytic astrocytoma, low } \\
\text { grade }\end{array}$ & Third ventricle & 1 & $\mathrm{NS}+\mathrm{RT}+\mathrm{CT}$ & $\mathrm{TPHD}+\mathrm{DI}$ & & 1 & \\
\hline 4 & $\mathrm{M}$ & 73 & 27.9 & Syncytial meningioma & Clinoid & 1 & NS & TPHD & & 9 & Hyperpolactinemia \\
\hline 5 & $M$ & 68 & 27.2 & Meningioma & Third ventricle, suprasellar & 1 & $\mathrm{NS}+\mathrm{RT}$ & TPHD & & 4 & \\
\hline 6 & $\mathrm{~F}$ & 50 & 33.3 & Meningioma & Tuberculum sellae & 1 & NS & TPHD & & 1 & Hyperpolactinemia \\
\hline 7 & M & 43 & 30.1 & Hemangiopericytoma & Hypothalamus-pituitary & 1 & NS & TPHD & & 2 & \\
\hline 8 & M & 65 & 27.5 & Meningioma & Ethmoido-sphenoidal & 1 & NS & TPHD & & 5 & \\
\hline 9 & $\mathrm{M}$ & 47 & 22.5 & Chondrosarcoma & Sphenoid wing & 1 & $\mathrm{NS}+\mathrm{RT}$ & TPHD & & 20 & \\
\hline 10 & $\mathrm{~F}$ & 38 & 23.0 & Osteosarcoma & Clinoid & 1 & $\mathrm{NS}+\mathrm{RT}+\mathrm{CT}$ & TPHD & & NA & \\
\hline 11 & $\mathrm{~F}$ & 69 & 25.3 & Meningioma & NA & NA & $\mathrm{NS}+\mathrm{RT}$ & TPHD & & 10 & Hyperpolactinemia \\
\hline 12 & $\mathrm{M}$ & 42 & 31.4 & Anaplastic astrocytoma & Frontal & 2 & $\mathrm{NS}+\mathrm{RT}+\mathrm{CT}$ & $\begin{array}{c}\text { ACTH-TSH- } \\
\text { LH/FSH }\end{array}$ & & 3 & \\
\hline 13 & $\mathrm{~F}$ & 42 & 23 & Ependymoma & Left parietal & 3 & $\mathrm{NS}+\mathrm{RT}$ & $\begin{array}{l}\mathrm{ACTH}- \\
\mathrm{LH} / \mathrm{FSH}\end{array}$ & & 21 & Hyperpolactinemia \\
\hline 14 & $\mathrm{M}$ & 64 & 26.7 & Gliosarcoma & Fronto-parietal & 2 & $\mathrm{NS}+\mathrm{RT}$ & GH-LH/FSH & & 1 & Glucocorticoid treatme \\
\hline 15 & $\mathrm{~F}$ & 30 & 24.5 & Gemistocytic astrocytoma & Left fronto-parietal & 2 & $\mathrm{NS}+\mathrm{RT}+\mathrm{CT}$ & $\mathrm{GH}-\mathrm{LH} / \mathrm{FSH}$ & & 1 & Glucocorticoid treatmen \\
\hline 16 & $\mathrm{~F}$ & 29 & 23.4 & Neurocytoma & $\begin{array}{l}\text { Third ventricle, left lateral } \\
\text { ventricle }\end{array}$ & 1 & $\mathrm{NS}+\mathrm{RT}+\mathrm{CT}$ & $\mathrm{LH} / \mathrm{FSH}$ & & 4 & \\
\hline 17 & M & 61 & 43.0 & Meningioma & Left parietal & 3 & NS & $\mathrm{LH} / \mathrm{FSH}$ & & 1 & \\
\hline 18 & $\mathrm{~F}$ & 32 & NA & Fibrillar astrocytoma & Right temporo-parietal & 3 & $\mathrm{NS}+\mathrm{CT}$ & LH/FSH & & 5 & \\
\hline 19 & $M$ & 26 & 29.9 & Ependymona & Fourth ventricle & 4 & $\mathrm{NS}+\mathrm{RT}+\mathrm{CT}$ & $\mathrm{LH} / \mathrm{FSH}$ & & 1 & Glucocorticoid treatment \\
\hline 20 & $\mathrm{~F}$ & 20 & 17.1 & Medulloblastoma & Fourth ventricle & 4 & $\mathrm{NS}+\mathrm{RT}+\mathrm{CT}$ & LH/FSH & Thyroid & 13 & \\
\hline 21 & $\mathrm{~F}$ & 60 & 23.0 & Meningioma & Frontal & 2 & NS & $\mathrm{GH}$ & & 0.8 & \\
\hline 22 & $M$ & 79 & 24.5 & Meningioma & Parasagittal, left frontal & 2 & NS & $\mathrm{GH}$ & & 1 & \\
\hline 23 & $\mathrm{~F}$ & 58 & 37.9 & Oligodendroglioma & Right frontal & 2 & $\mathrm{NS}+\mathrm{RT}+\mathrm{CT}$ & GH & & 1 & \\
\hline 24 & $\mathrm{M}$ & 64 & 23.5 & Glioblastoma & Left temporo-parietal & 3 & $\mathrm{NS}+\mathrm{RT}$ & GH & & NA & \\
\hline 25 & $\mathrm{M}$ & 38 & 27.2 & Medulloblastoma & Cerebellum & 4 & $\mathrm{NS}+\mathrm{RT}$ & $\mathrm{GH}$ & & 16 & \\
\hline 26 & M & 22 & 25.4 & Ependymoma & Fourth ventricle & 4 & $\mathrm{NS}+\mathrm{RT}+\mathrm{CT}$ & $\mathrm{GH}$ & $\begin{array}{l}\text { Gonads, } \\
\text { thyroid }\end{array}$ & 18 & \\
\hline
\end{tabular}

NS, neurosurgery; RT, radiotherapy; CT, chemotherapy; TPHD, total pituitary hormone deficit; DI, diabetes insipidus; ACTH, adrenocorticotropic hormone; TSH, thyroid-stimulating hormone; LH, luteinizing hormone; FSH, follicle-stimulating hormone; GH, growth hormone. 


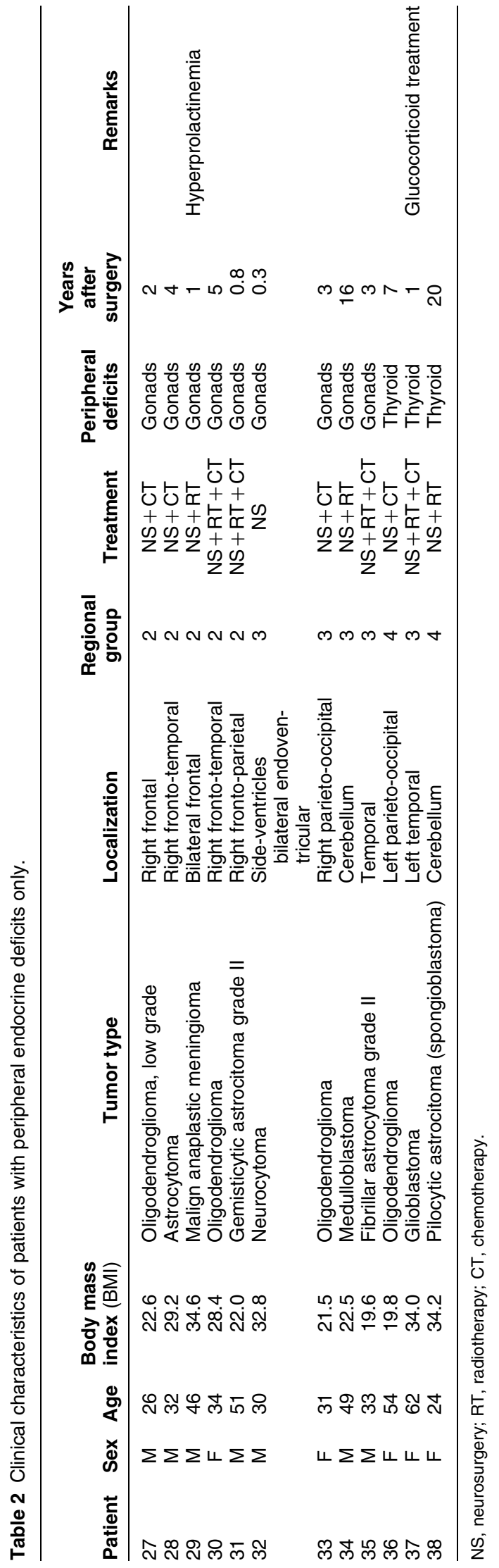

Patients with and without hypopituitarism showed no difference in age (hypopituitarism vs no hypopituitarism: 47.3 vs 43.5 years; $P=0.31)$, BMI $(26.7$ vs 26.4 ; $P=0.78)$, or time after surgery $(4.6$ vs 5.8 years; $P=0.83$ ). Patients with GHD showed no difference in BMI (GHD vs no GHD: 26.3 vs $26.6 ; P=0.86$ ) or time after surgery ( 5.4 vs 4.9 years, $P=0.71$ ), but were older $(51.5 \pm 4.0$ vs $42.4 \pm 1.9$ years; $P=0.02)$ and had lower IGF-I levels (119.1 \pm 15.6 vs $201.2 \pm 11.9 \mathrm{ng} / \mathrm{ml}$; $P<0.001)$ than those without GHD. IGF-I levels were below the age-related 25th centile and - 2SDS in 52.6 and $21.1 \%$ respectively of the patients with GHD, and in 14.3 and $6.0 \%$ respectively of the patients without GHD. Peak GH levels correlated negatively with BMI $(r=0.43$; $P<0.01)$ but not with time after surgery $(r=-0.02$; $P=0.87$ ) in the whole population. When only patients who have received RT, among others, were analyzed; there was still no correlation of peak $\mathrm{GH}$ with time after surgery $(r=-0.06 ; P=0.71)$. In men, there were no significant correlations of testosterone with BMI $(r=0.06, P=0.70)$ or age $(r=0.17 ; P=0.28)$.

Fourteen $(20.6 \%$ of all $)$ patients had peripheral hormone deficiencies (isolated primary hypogonadism in $13.2 \%$, isolated primary hypothyroidism in $5.9 \%$, combined in $1.5 \%)$. Of these, 12 out of 14 (17.6\% of all) patients had only peripheral deficiencies, whereas two patients had both peripheral and central hormone deficiencies. The corresponding percentages of peripheral hormonal impairments were as follows: NS, $5.9 \%$; NS and RT, 12.5\%; NS and CT, 57.1\%; and NS, RT, and CT, 30\%. Patients with peripheral hormone deficits were younger than those without peripheral deficits (36.7 \pm 3.5 vs $47.1 \pm 2.0$ years; $P=0.02$ ) but showed no difference in BMI $(26.0$ vs $26.6 ; P=0.65)$. The percentages of females among those with and without peripheral hormone deficits were 42.9 and $40.7 \%$ respectively.

\section{Discussion}

In this study, we have shown that more than half of the patients operated on for non-pituitary intracranial tumors have hormonal disturbances. Almost 40\% had hypopituitarism and another $20 \%$ suffered from peripheral endocrine alterations. The percentages of pituitary alterations were higher in patients with tumors located close to the sella turcica. The fact that hypopituitarism was more common in patients who underwent NS only than in those with additional other treatments indicates that NS played a main role in the development of hypopituitarism. To date, studies have mainly focused on the effects of surgery on tumors derived from pituitary tissue or in close proximity to the hypothalamic-pituitary region (1-3). Here, pituitary insufficiency is very common and is a good clinical practice to evaluate endocrine function before and after surgery. Other studies have concentrated on the effects of RT of 


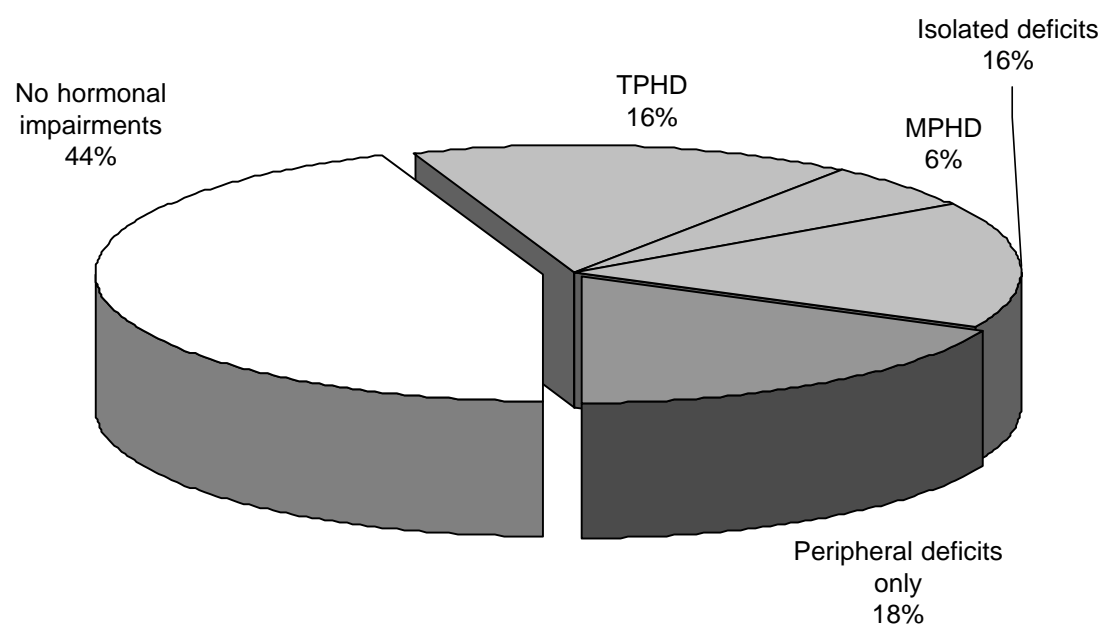

Figure 1 Prevalence of hormonal disturbances. TPHD, total pituitary hormone deficit; MPHD, multiple pituitary hormone deficit. intracranial tumors on endocrine function (6), showing that hypopituitarism is very common after irradiation for pituitary tumors, nasopharyngeal cancers, and childhood cancers. A more recent study has shown that irradiation of adult intracranial tumors also put patients at high risk of hypopituitarism, albeit less high than the previously mentioned patient groups (7).

In our study, in contrast, we have addressed a different aspect: we wanted to evaluate endocrine function in patients primarily operated on for non-pituitary tumors.
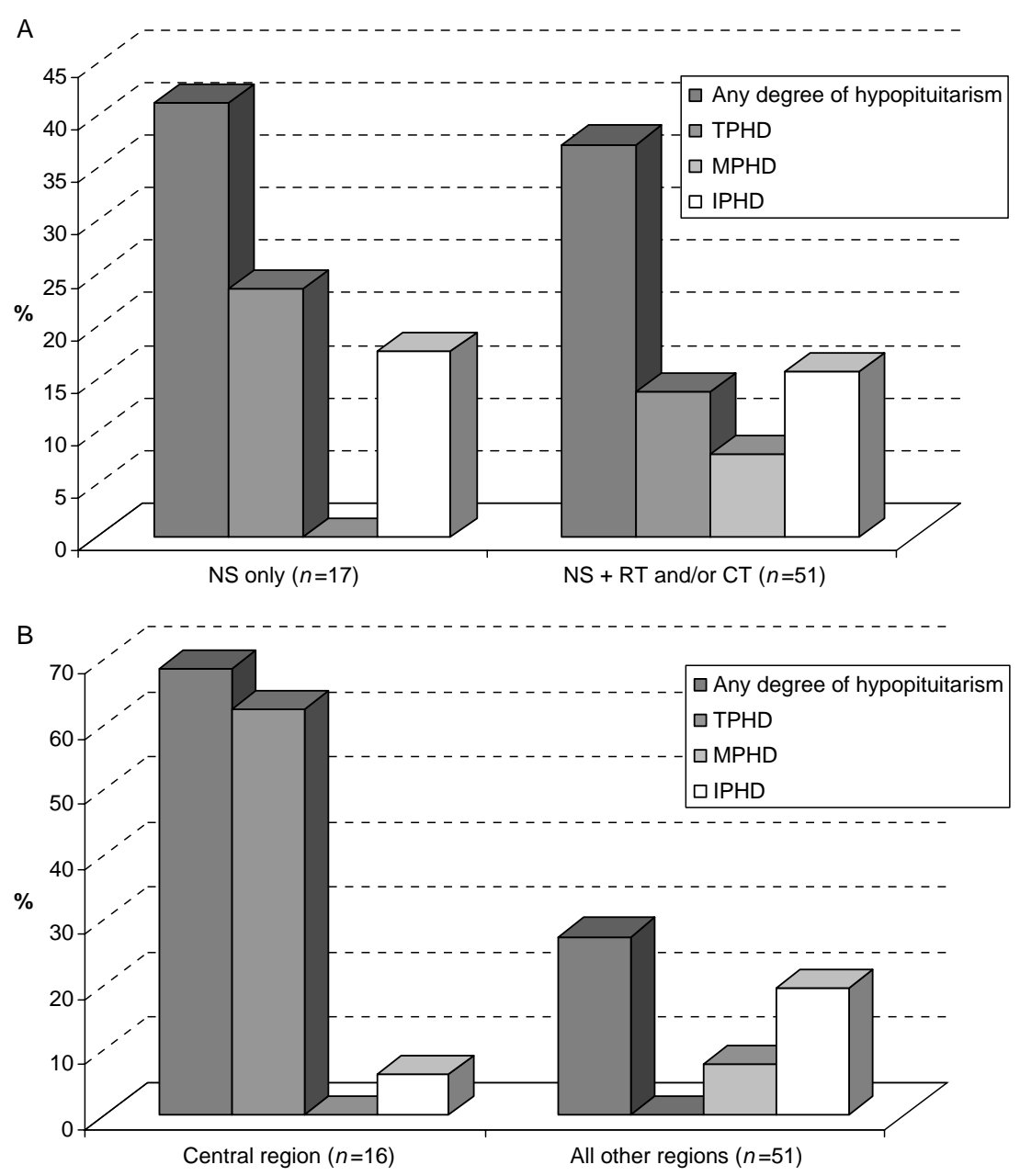

Figure 2 Percentages of hypopituitarism according to treatment $(A)$ and regional distribution of tumors (B). The central region contains all tumors of the following brain areas: sphenoid, clinoid, tuberculum sellae, sella, supra-, infra- and parasellar, and third ventricle. In one patient, no information on localization was available. TPHD, total pituitary hormone deficit; MPHD, multiple pituitary hormone deficit; IPHD, isolated pituitary hormone deficit; NS, neurosurgery; $\mathrm{RT}$, radiotherapy; CT, chemotherapy. 
As could be expected, the prevalence of various degrees of hypopituitarism was very high in those patients operated on for tumors in close proximity to the hypothalamicpituitary region. More than two-thirds of these were affected. Additionally, these patients were also most severely affected, with the majority displaying total hypopituitarism. However, more than a quarter of those patients with tumors not directly neighboring the hypothalamic-pituitary region, also showed pituitary alterations. This is particularly important, as these patients normally are not considered for endocrine evaluation. The symptoms of hypopituitarism are often unspecific and can be additionally masked by the sequalae of NS, RT, and CT in these patients. Therefore, they are likely to be overlooked if endocrine dysfunction is not actively searched for. Diabetes insipidus and hyperprolactinemia were more common in patients with anterior hypopituitarism and their presence should promote further endocrine evaluation. However, the majority of hypopituitary patients did not show these signs. Therefore, the absence of diabetes insipidus or hyperprolactinemia should not preclude patients from being tested.

Many possible causes of hypothalamic-pituitary damage must be taken into account. The tumor itself might cause damage by mass effects or infiltration. Moreover, possibly, metastatic destruction of the hypothalamus or pituitary gland could play a role in some cases. Surgical interventions might cause damage not only at the tumor site, but also in the surrounding brain tissue and the pathway of access. The detrimental effects of RT are well recognized (6), and could additionally impair pituitary function in our patients. Possibly, CT could also play a role. It has to be underlined that the exploratory design of our study did not allow to analyze the effects of different surgical approaches on pituitary function in these patients. Also, it is not clear whether those treated with NS only were treated in more radical and invasive way that might have caused more hypopituitarism than in other patients. Further studies are needed to clarify this issue.

The pattern of pituitary dysfunction found in our study was similar to that of classical hypopituitarism caused by pituitary masses: TPHD and MPHD were the most common alterations and the sequence of IPHD with impairment of LH/FSH and $\mathrm{GH}$ being more common than of ACTH and TSH. This is in contrast with the patterns of hypopituitarism found in brain damage due to traumatic brain injury or aneurysmatic subarachnoid hemorrhage. Here, mainly single axis deficiencies and no clear hierarchies of impairments were found (8-11). It is also different to the effects of RT that mainly affect the somatotropic axis and, less frequently, the gonadotropic axis (6).

The correct diagnosis of GHD has been subject of much debate in the recent years. The GHRH + arginine test has been recently criticized for lack of sensitivity for hypothalamic GHD in the first 5 years after cranial irradiation (16). The classical test for the diagnosis of GHD that includes the hypothalamus is the insulintolerance test (17). However, this test is contraindicated in patients with epileptic seizures. As epileptic seizures are very common in patients with brain tumors, we could not use this test in our study. Other tests that include hypothalamic functions such as the glucagon test are less well evaluated and have been criticized for lack of specificity (8). In the light of the recently highlighted BMI-dependence of the GHRH + arginine test (18), we have used the BMI-dependent cut offs that were newly established in our laboratory (15). The fact that IGF-I levels were significantly lower and beneath the 25th centile in more than half of the patients classified as GH deficient, further supports the notion that these patients were really $\mathrm{GH}$ deficient. Even though the GHRH + arginine test might underestimate the true prevalence of GHD, it was still the second most common deficiency in our population.

We have not carried out dynamic testing for the corticotropic axis. In the recent years, it has been stressed that stimulation tests should be carried out in unclear cases and a meta-analysis has shown that the ACTH test might be a reliable alternative to the insulin-tolerance test for the diagnosis of secondary hypocortisolism (19). We cannot exclude that we have underestimated the percentage of adrenal insufficiency in this exploratory study. Possibly, this should be addressed in future research.

The correct diagnosis of male hypogonadism has been debated. Whereas some authors stress the importance of SHBG and free testosterone, total testosterone levels are still recommended as the most standardized method (20) for diagnosing male hypogonadism. With $3 \mu \mathrm{g} / \mathrm{l}$, we have used a rather conservative threshold for the diagnosis of hypogonadism.

We found no difference in time after surgery in patients with hypopituitarism or GHD, compared with nonaffected subjects. In subjects irradiated for brain tumors, a long interval after treatment has been found to be a risk factor for both hypopituitarism (7) and $\operatorname{GHD}(7,16)$. The fact that we found no difference in time after treatment further supports the notion that radiation was not the main cause for hypopituitarism in our sample. Irradiation causes progressive impairment of pituitary function over many years, whereas surgery causes immediate destruction. If we assume that NS or the tumor itself is the cause of hypopituitarism, time after surgery should not affect the probability of hypopituitarism.

We have additionally found a substantial proportion of primary endocrine alterations. Among these patients, mostly hypogonadism was found. Some patients also had primary hypothyroidism without TPO antibodies, indicating that hypothyroidism was not caused by autoimmune thyroiditis. Peripheral endocrine dysfunction after chemotherapy and irradiation has been considered mainly in treatment for childhood cancer (21). Our 
results show that these dysfunctions also affect patients treated in adulthood to a substantial degree.

Taken together, our results show that endocrine dysfunction is very common after surgical treatment of intracranial tumors. These results indicate that not only patients with hypothalamic-pituitary, but also those with other intracranial tumors should be considered for endocrine evaluation on a regular basis. First, recommendations by interdisciplinary expert rounds for the endocrine evaluation and treatment of patients with brain injury and subarachnoid hemorrhage have been published $(22,23)$. Perhaps, these should be extended to patients with brain tumors.

\section{References}

1 Nomikos P, Ladar C, Fahlbusch R \& Buchfelder M. Impact of primary surgery on pituitary function in patients with nonfunctioning pituitary adenomas - a study on 721 patients. Acta Neurochirurgica 2004146 27-35.

2 Corneli G, Baldelli R, Di Somma C, Rovere S, Gaia D, Pellegrino M, Gasco V, Durante C, Grottoli S, Colao A, Tamburrano G, Lombardi G, Ghigo E \& Aimaretti G. Occurrence of GH deficiency in adult patients who underwent neurosurgery in the hypothalamus-pituitary area for non-functioning tumour masses. Growth Hormone and IGF Research 200313 104-108.

3 Honegger J, Buchfelder M \& Fahlbusch R. Surgical treatment of craniopharyngiomas: endocrinological results. Journal of Neurosurgery $199990251-257$.

4 Littley MD, Shalet SM, Beardwell CG, Ahmed SR, Applegate G \& Sutton ML. Hypopituitarism following external radiotherapy for pituitary tumours in adults. Quarterly Journal of Medicine 198970 $145-160$.

5 Lam KSL, Tse VKC, Wang C, Yeung RTT \& Ho JHC. Effects of cranial irradiation on hypothalamic-pituitary function - a 5-year longitudinal study in patients with nasopharyngeal carcinoma. Quarterly Journal of Medicine $1991 \mathbf{7 8} 165-176$.

6 Darzy KH \& Shalet SM. Hypopituitarism after cranial irradiation. Journal of Endocrinological Investigation 200528 78-87.

7 Agha A, Sherlock M, Brennan S, O'Conor SA, O'Sullivan E, Rogers B, Faul C, Rawluk D, Tormey W \& Thompson CJ. Hypothalamic-pituitary dysfunction after irradiation of nonpituitary brain tumors in adults. Journal of Clinical Endocrinology and Metabolism 200590 6355-6360.

8 Agha A, Rogers B, Sherlock M, O'kelly P, Tormey W, Phillips J \& Thompson CJ. Anterior pituitary dysfunction in survivors of traumatic brain injury. Journal of Clinical Endocrinology and Metabolism $2004 \mathbf{8 9} 4929-4936$.

9 Aimaretti G, Ambrosio MR, Di Somma C, Gasperi M, Cannavo S, Scaroni C, Fusco A, Del Monte P, De Menis E, Faustini-Fustini M, Grimaldi F, Logoluso F, Razzore P, Rovere S, Benvenga S, Degli Uberti EC, De Marinis L, Lombardi G, Mantero F, Martino E, Giordano G \& Ghigo E. Residual pituitary function after brain injury-induced hypopituitarism: a prospective 12-month study. Journal of Clinical Endocrinology and Metabolism 200590 6085-6092.
10 Schneider HJ, Schneider M, Saller B, Petersenn S, Uhr M, Husemann B, von Rosen F \& Stalla GK. Prevalence of anterior pituitary insufficiency 3 and 12 months after traumatic brain injury. European Journal of Endocrinology 2006154 259-265.

11 Kreitschmann-Andermahr I, Hoff C, Saller B, Niggemeier S, Pruemper S, Hutter BO, Rohde V, Gressner A, Matern S \& Gilsbach JM. Prevalence of pituitary deficiency in patients after aneurysmal subarachnoid hemorrhage. Journal of Clinical Endocrinology and Metabolism 200489 4986-4992.

12 Schneider M, Schneider HJ \& Stalla GK. Anterior pituitary hormone abnormalities following traumatic brain injury. Journal of Neurotrauma 200522 937-946.

13 Ghigo E, Aimaretti G, Gianotti L, Bellone J, Arvat E \& Camanni F. New approach to the diagnosis of growth hormone deficiency in adults. European Journal of Endocrinology 1996134 352-356.

14 Aimaretti G, Corneli G, Razzore P, Bellone S, Baffoni C, Arvat E, Camanni F \& Ghigo E. Comparison between insulin-induced hypoglycemia and growth hormone (GH)-releasing hormone+ arginine as provocative tests for the diagnosis of GH deficiency in adults. Journal of Clinical Endocrinology and Metabolism $1998 \mathbf{8 3}$ $1615-1618$.

15 Corneli G, Di Somma C, Baldelli R, Rovere S, Gasco V, Croce CG, Grottoli S, Maccario M, Colao A, Lombardi G, Ghigo E, Camanni F \& Aimaretti G. The cut-off limits of the GH response to GH-releasing hormone-arginine test related to body mass index. European Journal of Endocrinology 2005153 257-264.

16 Darzy KH, Aimaretti G, Wieringa G, Gattamaneni HR, Ghigo E \& Shalet SM. The usefulness of the combined growth hormone (GH)releasing hormone and arginine stimulation test in the diagnosis of radiation-induced GH deficiency is dependent on the postirradiation time interval. Journal of Clinical Endocrinology and Metabolism $2003 \mathbf{8 8}$ 95-102.

17 Hoffman DM, O'Sullivan AJ, Baxter RC \& Ho KKY. Diagnosis of growth hormone deficiency in adults. Lancet $19943 \mathbf{3 4 3}$ 1064-1068.

18 Bonert VS, Elashoff JD, Barnett P \& Melmed S. Body mass index determines evoked growth hormone $(\mathrm{GH})$ responsiveness in normal healthy male subjects: diagnostic caveat for adult GH deficiency. Journal of Clinical Endocrinology and Metabolism 2004 89 3397-3401.

19 Dorin RI, Qualls CR \& Crapo LM. Diagnosis of adrenal insufficiency. Annals of Internal Medicine 2003139 194-204.

20 Nieschlag E, Behre HM, Bouchard P, Corrales JJ, Jones TH, Stalla GK, Webb SM \& Wu FC. Testosterone replacement therapy: current trends and future directions. Human Reproduction Update $200410409-419$.

21 Livesevey ES, Hindmarsh PC, Brook CG, Whitton AC, Bloom HJ, Tobias JS, Godlee JN \& Britton J. Endocrine disorders following treatment of childhood brain tumours. British Journal of Cancer $199061622-625$.

22 Ghigo E, Masel B, Aimaretti G, Leon-Carrion J, Casanueva FF, Dominguez-Morales MR, Elovic E, Perrone K, Stalla G, Thompson C \& Urban R. Consensus guidelines on screening for hypopituitarism following traumatic brain injury. Brain Injury $200519711-724$.

23 Schneider HJ, Stalla GK \& Buchfelder M. Expert meeting: hypopituitarism after traumatic brain injury and subarachnoid haemorrhage. Acta Neurochirurgica 2006148 449-456.

Received 30 May 2006

Accepted 31 July 2006 